\title{
Correlation study on operation of the wet FGD system and incomplete coal combustion
}

\author{
LUCICA ANGHELESCU * \\ BOGDAN DIACONU * \\ MIHAI CRUCERU * \\ GEORGE ȘERBAN ** \\ *Energy, Environment and Agroturism Department \\ University Constantin Brâncuși of Tg-Jiu \\ Address: Eroilor 30, Tg-Jiu, Gorj, \\ ROMANIA \\ **Complexul Energetic Oltenia, SE Rovinari
}

\begin{abstract}
A Wet Flue Gas Desulfurization (WFGD) system operating at thermal power plant Rovinari (Romania), was considered in this study in an attempt to establish mutual or uni-directional influences between the performance of the sulphur removal process and the quality of the combustion process. Although in theory the WFGD system operates automatically with parameters controlled in such way that optimum removal efficiency is obtained, some parameters cannot be fully controlled, especially those that could not be anticipated at the design of the WFGD system. Sulphur removal systems are customizable to some extent but cannot provide an optimum solution for any plant, given the large range of differences between various plants. Coal quality is such a parameter, for which a large range of values and high standard deviation exists. Incomplete combustion is a serious issue caused by low coal quality resulting in significant losses. Briefly, incomplete combustion process is equivalent to coal that is injected in the furnace but does not undergo combustion or undergoes a partial combustion, being eventually evacuated from the boiler. This study attempts to identify quantitative and qualitative influence of incomplete combustion on the operation of the FGD system.
\end{abstract}

Key-Words: - power plant system, bottom ash, sulphur oxides, incomplete combustion, unburned carbon.

Received: February 22, 2019. Revised: May 13, 2020. Re-revised: May 20, 2020. Accepted: May 21, 2020.

Published: May 29, 2020.

\section{Introduction}

\subsection{FGD technologies - state of the art}

Cleaner production has established as an industrial standard, with coal utilization technologies, from extraction and pre-processing to ash management, making efforts to align to the standards regarding energy expenditure and environmental impact.

Flue gas released into the environment is a critical element in assessing the environmental impact of coal-fired power plants, with tight limits for pollutants concentration (sulphur and nitrogen oxides, flying ash FA).

Modern flue gas cleaning technologies reached performances that comply even with the most restrictive environment regulations. A recent review study on FGD technologies [1] points out advantages and disadvantages of each technique and gives a thorough report on the state of the art. An important issue discussed in [1] is the presence of hazardous elements in the end product - gypsum, such as arsenic, mercury, cadmium, lead and selenium.
Sulphur oxides removal technologies exist on the market for over a century [2]. Three main approaches exist: (1) removal of sulphur from fuel before combustion (2) in-situ removal of sulphur oxides during combustion process and (3) postcombustion treatment of the flue gas. Various coal desulfurization approaches have been described in [3].

Removal of sulphur from coal prior to combustion is a technique that does not require any modification of the combustion system (boiler and fuel pre-processing and injection systems). On the other hand, pre-treatment of coal in order to remove Sulphur is itself a process with significant impact on the environment [4].

Sulphur removal during combustion phase is a technologically simple process consisting of injection of dolomite in the boiler furnace [5]. The chemical reactions taking place during combustion and resulting in sulphur being bound in solid compounds (sulphate) are the following:

$\mathrm{CaO}+\mathrm{SO}_{2}+{ }_{2}^{1} \mathrm{O}_{2} \rightarrow \mathrm{CaSO}_{4}$

or limestone $\mathrm{CaCO}_{3}[6]$ :

$\mathrm{CaCO}_{3} \rightarrow \mathrm{CaO}+\mathrm{CO}_{2}$ 


$$
\mathrm{CaO}+\mathrm{SO}_{2}+\frac{1}{2} \rightarrow \mathrm{CaSO}_{4}
$$

Pre-combustion desulfurization of coal and sulphur removal during combustion are simple techniques with the dominant advantage of simplicity and low investment cost [7]. However, since the introduction of these techniques, the legal requirements regarding sulphur emission became increasingly tight. Nowadays, the two techniques are obsolete and cannot fully comply with actual sulphur concentration limits in flue gas.

Higher sulphur removal performance is achieved through Wet Flue Gas Desulfurization (FGD) method [8]. Wet FGD method is the most widely used because of its high $\mathrm{SO}_{2}$ removal efficiency, reliable and low utility consumption [9].

The sulphur oxide removal mechanism in wet FGD process can be described as follows [10]: $\mathrm{SO}_{2}$ diffuses through the gas phase to a liquid surface, where it dissolves and is transferred by diffusion or convective mixing into the liquid phase.

The rate of $\mathrm{SO}_{2}$ diffusion depends on a number of factors such as the solubility of $\mathrm{SO}_{2}$ in the liquid and how far the system is from equilibrium state [11]. The chemical reactions occurring in wet FGD process can be resumed as follows [10]:

$$
\begin{aligned}
& \text { Absorber: } \mathrm{SO}_{2}+\mathrm{H}_{2} \mathrm{O} \rightarrow \mathrm{H}_{2} \mathrm{SO}_{4} \\
& \mathrm{CaCO}_{3}+\mathrm{H}_{2} \mathrm{SO}_{4} \rightarrow \mathrm{Ca}\left(\mathrm{HSO}_{3}\right)_{2}+\mathrm{CO}_{2}+\mathrm{H}_{2} \mathrm{O} \\
& \text { Tank: }
\end{aligned}
$$

$$
\mathrm{Ca}\left(\mathrm{HSO}_{3}\right)_{2}+\mathrm{O}_{2}+2 \mathrm{H}_{2} \mathrm{O} \rightarrow
$$

$\rightarrow \mathrm{CaSO}_{4} \cdot 2 \mathrm{H}_{2} \mathrm{O}+\mathrm{H}_{2} \mathrm{SO}_{4}$

$\mathrm{CaCO}_{3}+\mathrm{H}_{2} \mathrm{SO}_{4}+\mathrm{H}_{2} \mathrm{O} \rightarrow \mathrm{CaSO}_{4} \cdot 2 \mathrm{H}_{2} \mathrm{O}+\mathrm{CO}_{2}(7)$

Fine tuning and improvement approaches of Wet FGD method include addition of $\mathrm{MgO}$ [11], formic and adipic acids [12], etc.

Incomplete coal combustion, especially in the case of low quality coal, is an issue frequently encountered in coal-fired power plants. It not only represents a loss but it influences other processes, such as ash quality. In this paper, an attempt to study the influence of incomplete combustion on the effectiveness of the Wet FGD system is carried out. To the authors' knowledge, this is the first such study in the literature. The study is grounded by the following arguments:

I. The Wet FGD system is designed to operate with flue gas resulting from quasi-complete coal combustion, i.e. traces of $\mathrm{CO}$, hydro-carbons and other gaseous compounds that result from incomplete coal combustion. However, completeness of combustion cannot be fully predicted since it depends on many random factors, such as momentary coal quality. As a result, the flue gas reaching the FGD reactor contains highly reactive components that were not considered in the FGD design studies.

II. Incomplete coal combustion determines changes in the temperature regime of the flue gas. Although the FGD system (fully automated) is designed to cope with a range of flue gas temperatures, it is expected that deviation from the optimum regime would result in higher reactive consumption (limestone) and a drop in the sulphur removal efficiency.

III. Small coal particles that undergo incomplete combustion and leave the furnace with the flue gas may not be retained in the electrostatic precipitator due to aero-dynamic and electrostatic properties different from those of ash. As a result, such particles can reach the FGD reactor where they interfere both chemically and physically with the process. This can reduce the effectiveness of sulphur removal process and on the other hand, coal particles can spoil significantly the quality of gypsum.

\subsection{Combustion mechanism of coal particle in the furnace}

Combustion of a coal particle is a complex thermos-chemical process, which can be broken down in several phases as follows, in accordance with the characteristic physical processes [13], [14]:

- Dehydration due to temperature

- Release of the volatile matter by means of thermos-chemical break down

- Combustion of the volatile matter and formation of coke

- Combustion of fixed carbon from coke and generation of ash

There is no time differentiation between the phases of the combustion process but rather they overlap partially, in the sense that the next phase begins shortly before the previous phase end.

The extent to which they overlap depends on several factors, such as the type of the boiler, coal quality, pre-processing of coal prior to injection in the boiler. The phases of combustion can be illustrated in a graphical form [15] (Figure 1). 


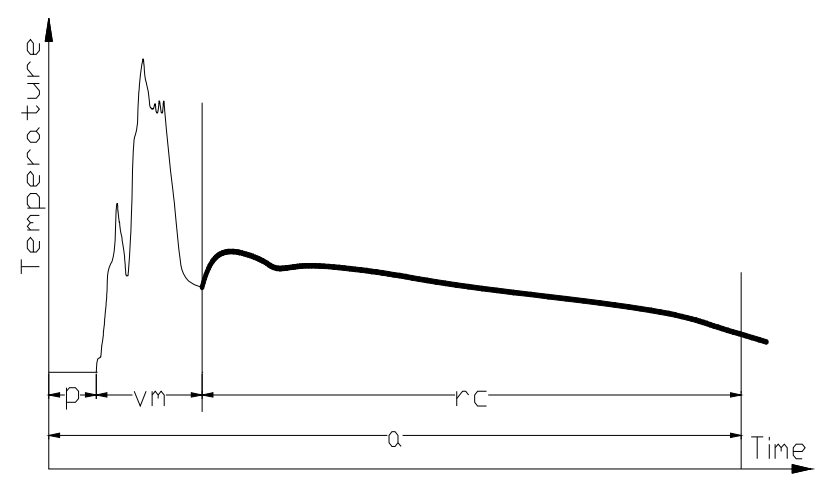

Fig. 1. Combustion process dynamics for a typical coal particle

The total combustion time $\tau_{\mathrm{a}}$ is given by:

$$
\tau_{\mathrm{a}}=\tau_{\mathrm{p}}+\tau_{\mathrm{mv}}+\tau_{\mathrm{rc}}
$$

The characteristic times are as follows:

- Thermal preparation of the particle $\tau_{p}$ : the particle heats up from the initial temperature to the volatile matter VM self-combustion temperature. During this phase complete elimination of water takes place and partial release of volatile matter.

- Release of VM and effective combustion $\tau_{v m}$; when the particle reaches the VM selfcombustion temperature, these burn and the temperature increases steeply. Due to the combustion speed much higher than VM release speed the temperature goes down and the process resumes.

- Combustion of the solid residue (coke or fixed carbon), $\tau_{\mathrm{rc}}$. It is a process with continuous decrease of temperature until the combustible matter is exhausted.

The complete combustion requires the following condition:

$$
\tau_{\mathrm{s}} \geq \tau_{\mathrm{a}}
$$

where $\tau_{s}$ is the stagnation time of the particle in the furnace, which can be approximated as follows:

$$
\tau_{\mathrm{s}}=\frac{\mathrm{H}}{\mathrm{w}_{\mathrm{p}}}
$$

where $\mathrm{H}$ is the length of the particle path, which can be considered equal to the furnace height and $w_{p}$ is the particle velocity, which can be approximated equal to the flue gas velocity.

The total combustion time $\tau_{\mathrm{a}}$ depends on the particle diameter:

$$
\tau_{\mathrm{a}}=\mathrm{f}\left(\mathrm{d}_{\mathrm{p}}^{2}\right)
$$

The main factors that cause incomplete combustion are:

- Large size of the coal particle

- Height of the furnace too small

- Insufficient removal of humidity
- Insufficient access of oxygen to the coal particle

\section{Specific factors that influence incomplete combustion at Rovinari power plant}

The actual conditions at the $1035 \mathrm{t} / \mathrm{h}$ boilers at Rovinari power plant deviate to random degrees from the theoretical considerations presented in the previous sections.

Coal-fired power plant Rovinari differs from the mainstream in the following points:

- Very low coal quality. The plant is located in such way that it takes advantage of the low coal transport distance. Low cost of coal transportation offsets to some degree its low quality

- Insufficient separation of sterile from coal. Open pit excavation conditions do not allow complete elimination of sterile material from the production flow. Sterile ends up in the coal mill, interfering with the milling process and causing improper milling and particles with large dimensions are delivered to the coal burners.

- Advanced wear of the coal mills. Although the wear level is acknowledged, a number of factors related mainly to management and keeping maintenance cost at a low level prevent shut down for maintenance. The wear rate is much higher than expected due to the coal quality.

Incomplete combustion caused by the factors described above results in unburned organic matter in both fly ash (FA) and bottom ash (BA). At Rovinari power plant a periodic determination program for unburned matter in FA and BA has been implemented. The chemical analysis, sampling and validation are performed by methods based on EN and ISO standards. The unburned matter content in FA and BA is carried out according to the provisions of the national standard STAS 10274/15$75[6]$.

\section{Unburned carbon and FGD performance - a quantitative analysis}

Incomplete combustion of the coal injected in the furnace reduces the amount of sulphur that is oxidized and contributes to the formation of sulphur oxides. The term "retention" means actually an indirect retention here as it is a secondary effect of incomplete combustion [13]. Thus, incomplete combustion of coal is equivalent to a lower amount of sulphur that react with oxygen and forms sulphur 
oxides. The amount of sulphur retained through this mechanism is given by the following equation:

$\mathrm{m}_{\text {sulfur retained }}=\mathrm{B} \frac{\mathrm{A}_{\mathrm{i}}}{100}\left[\mathrm{a}_{\mathrm{BA}} \frac{\mathrm{s}_{\mathrm{BA}}}{100}+\mathrm{a}_{\mathrm{FA}} \eta_{\mathrm{EP}} \frac{\mathrm{S}_{\mathrm{FA}}}{100}\right]$ (12) where $B$ is the fuel mass rate, $A_{i}$ is the initial content of ash, $\mathrm{S}_{\mathrm{BA}}$ is the BA sulfur content, $\mathrm{S}_{\mathrm{FA}}$ is the FA sulfur content and $\eta_{E P}$ is the efficiency of the electrostatic precipitators. $a_{B A}=0.2-$ the total ash percentage retained at the bottom of the boiler as $\mathrm{BA}, a_{B F A}=0.8$ the total ash percentage leaving the furnace as FA.

Table 1. Sulphur balance for 3 boilers at Rovinari power plant

\begin{tabular}{|c|c|c|c|c|c|c|c|c|c|c|}
\hline \multirow[t]{2}{*}{ B } & \multirow[t]{2}{*}{$\mathrm{S}_{\mathrm{i}}$} & \multirow[t]{2}{*}{$\mathrm{A}_{\mathrm{i}}$} & \multicolumn{2}{|c|}{$\begin{array}{c}\text { Total ash } \\
\text { breakdown in } \\
\text { BA/FA }\end{array}$} & \multicolumn{2}{|c|}{$\begin{array}{l}\text { Unburned } \\
\text { carbon in ash }\end{array}$} & \multirow[t]{2}{*}{$\begin{array}{l}\text { Unburned } \\
\text { coal }\end{array}$} & \multirow[t]{2}{*}{$\begin{array}{c}\text { Combustible } \\
\text { mass }\end{array}$} & \multirow[t]{2}{*}{$\begin{array}{l}\text { Sulphur } \\
\text { content } \\
\text { in } \\
\text { unburned } \\
\text { coal }\end{array}$} & \multirow[t]{2}{*}{$\begin{array}{l}\text { Wet } \\
\text { FGD } \\
\text { sulphur } \\
\text { removal } \\
\text { rate }\end{array}$} \\
\hline & & & $\mathrm{BA}$ & FA & $\mathrm{BA}$ & FA & & & & \\
\hline 1 & 2 & 3 & 4 & 5 & 6 & 7 & 8 & 9 & 10 & 11 \\
\hline $\mathrm{t}$ & $\%$ & $\%$ & \multicolumn{2}{|c|}{$\%$} & $\%$ & $\%$ & $\%$ & $\%$ & $t$ & $\%$ \\
\hline 227135 & 1.30 & 22.93 & 20.00 & 80.00 & 38.72 & 2.20 & 6.13 & 35.57 & 180.8 & 96.3 \\
\hline 226201 & 1.15 & 22.89 & 20.00 & 80.00 & 32.60 & 1.91 & 5.19 & 35.51 & 134.9 & 96.6 \\
\hline 217910 & 1.35 & 21.79 & 20.00 & 80.00 & 36.39 & 2.06 & 5.36 & 36.31 & 157.5 & 96.1 \\
\hline
\end{tabular}

The data in Table 1 presents the sulphur balance for boilers 3, 4 and 6 for one full month of operation (June 2016). In column 1 the total amount of fuel in tons is given. Initial sulphur and ash content of the coal is given in columns 2 and 3 respectively. The total amount of ash resulting from coal combustion is divided in BA - collected to the bottom of the furnace and disposed by hydraulic transport and FA - consisting of particles small enough to be carried by the flue gas, most of it

\begin{tabular}{|c|c|c|c|c|c|c|c|c|}
\hline \multirow[b]{2}{*}{ Ash } & \multirow[b]{2}{*}{ Carbon } & \multirow[b]{2}{*}{ Hydrogen } & \multirow[b]{2}{*}{ Nitrogen } & \multirow[b]{2}{*}{ Oxygen } & \multicolumn{2}{|c|}{ Combustible sulphur } & \multicolumn{2}{|c|}{ Total moisture } \\
\hline & & & & & $\begin{array}{l}\text { Organic } \\
\text { sulphur }\end{array}$ & $\begin{array}{c}\text { Inorganic } \\
\text { sulphur }\end{array}$ & $\begin{array}{l}\text { Hygroscopic } \\
\text { moisture }\end{array}$ & $\begin{array}{l}\text { Surface } \\
\text { moisture }\end{array}$ \\
\hline \multirow{3}{*}{$\begin{array}{l}\text { Mineral } \\
\text { mass }\end{array}$} & \multicolumn{5}{|c|}{ Organic mass } & & \multirow{4}{*}{\multicolumn{2}{|c|}{ Moisture }} \\
\hline & \multicolumn{6}{|c|}{ Combustible mass } & & \\
\hline & $\begin{array}{l}\text { Fixed } \\
\text { carbon }\end{array}$ & \multirow{2}{*}{\multicolumn{5}{|c|}{ Volatile matter }} & & \\
\hline & & & & & & & & \\
\hline
\end{tabular}

It can be noticed from Table 1 (column 9) that the combustible mass value (as defined in Table 2) has a lower value than the unburned carbon in BA. This is an important issue that results in a significant drop of the combustion efficiency, for which few solutions exists. Although a paradoxical situation, the value of carbon percentage in BA higher than the combustible mass is explained by the fact that BA only accounts for roughly $20 \%$ of the total ash generated. Thus, the absolute value of unburned carbon in BA is divided by a smaller quantity, resulting in a higher percentage value. This BA still has combustion properties.

In fact, it is a common practice implemented at thermal power plants in Romania fired with same being retained in electrostatic precipitators. The boiler manufacturer provides the BA and FA values in columns 4 and 5 respectively. The large value of the unburned carbon in BA (column 6) is caused by the factors described in Section 2. The value of the unburned carbon content is even comparable if not higher than the initial carbon in coal. The following table defines the meaning of combustible mass:

type of lignite (such as cogeneration plant Govora) that BA be re-burned. In such case the sulphur balance changes, which can influence the FGD system. Re-burning has some drawbacks however such as the fact that the BA contains also a significant amount of slag, which influences the milling process and the wear of the coal mills. Due to these considerations, no re-burning solution has been implemented at Rovinari power plant.

Unburned carbon can be also found in FA (Table 1, column7) in much lower amounts. This is because FA particles are small sized and spend enough time in the furnace so that combustion is almost complete. The total unburned coal (weighted sum of unburned carbon in BA and FA) is given in column 
8. The total amount of sulphur that does not react and does not form sulphur oxides is presented in column 10. The sulphur removal rate, calculated based on the effective amount of sulphur that enters the oxidation reactions and forms sulphur oxides is given in column 11.

The incomplete combustion phenomenon, which results in a significant amount of coal that does not react and consequently does not form sulphur oxides makes necessary to reconsider the operation of the wet FGD system. Two major influences of incomplete combustion on the operation of the FGD system can be observed:

- Incomplete coal combustion creates flue gas components that otherwise would not be present: CO, hydro-carbons, etc. Some of these gases have a high reactivity and can interfere with the processes occurring in the FGD reactor especially in the absorber

- Small unburned coal particles that escape the electrostatic precipitators can reach the FGD system and. These particles are unlikely to react chemically during the sulphur removal process (Eqs 4 - 7) and will end up in the final product (gypsum), lowering considerably its quality and rendering it unsuitable for the usual applications.

The $\mathrm{SO}_{2}$ emission at the inlet of the wet FGD system (absorber) must be corrected using the following equation:

$$
\mathrm{m}_{\mathrm{SO}_{2}}=\frac{\mathrm{M}_{\mathrm{SO}_{2}}}{\mathrm{M}_{\mathrm{S}}} \cdot \frac{\mathrm{S}_{\mathrm{c}}^{\mathrm{i}}}{100} B_{\text {actual }}\left(1-\eta_{1}\right) \cdot\left(1-\eta_{2}\right)
$$

where: $\mathrm{M}_{\mathrm{SO}_{2}}$ molecular mass of $\mathrm{SO}_{2}$

$\mathrm{M}_{\mathrm{S}}$ molecular mass of sulfur

$S_{\mathrm{c}}^{\mathrm{i}}$ initial content of sulfur in coal

$\mathrm{B}_{\text {actual }}$ actual coal flow rate that reacts and forms sulfur oxides

$\eta_{1}$ sulfur oxide fraction removed in the dust removal systems

$\eta_{2}$ sulfur oxide fraction corresponding to the unburned coal (retained in BA and FA)

The values of $\eta_{1}$ and $\eta_{2}$ are given in Table 3 .

Table 3. $\mathrm{SO}_{2}$ fraction removed

\begin{tabular}{|l|c|}
\hline \multicolumn{1}{|c|}{ Dust removal system } & $\eta_{1}$ \\
\hline $\begin{array}{l}\text { Electrostatic precipitators, cyclones, dry } \\
\text { filters }\end{array}$ & 0 \\
\hline $\begin{array}{l}\text { Wet dust removal system: } \\
\quad \begin{array}{l}\text { Scrubber with neutral pH water } \\
\text { Scrubber with alkaline pH water }\end{array}\end{array}$ & 0,015 \\
\hline
\end{tabular}

Sulphur oxide fraction corresponding to the unburned coal (retained in BA and FA) ranges between 0.1 and 0.2 .
Between August 2017 and July 2019 a study concerning the combustion efficiency was carried out at Rovinari power plant. One of the many components of the study was collection of data concerning the content of unburned matter in BA and FA. In Figure 2, monthly averaged values of total unburned coal and unburned carbon present in the FA are represented.

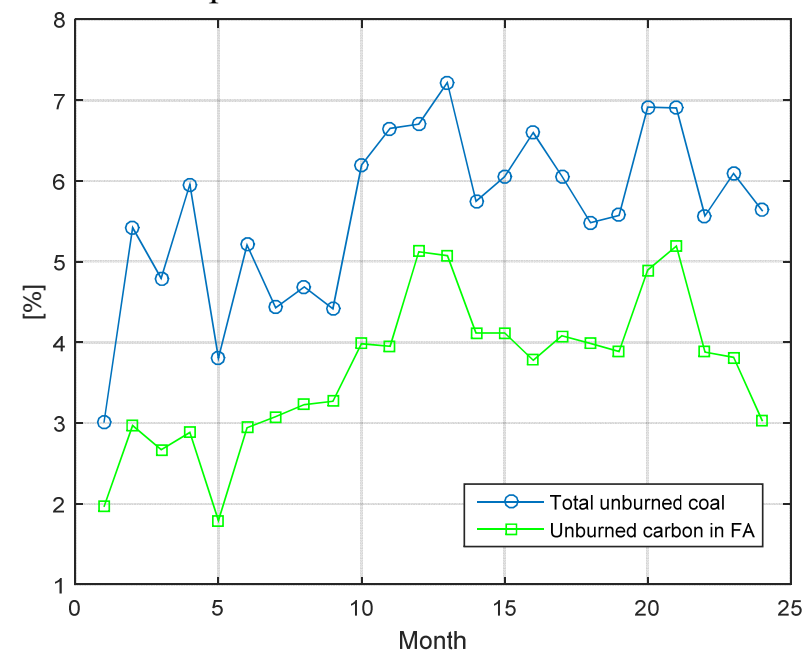

Fig. 2. Unburned coal and unburned carbon in FA

The data for total unburned coal and carbon present in the FA shows a similar trend. Performing a statistical analysis, the value of Pearson correlation coefficient is 0.864 , which suggest a significant correlation, as it was expected. The total unburned carbon is quantitatively found as:

- Unburned or partially burned coal particles in FA

- Unburned or partially burned coal particles in BA

- Carbon monoxide and hydro-carbon compounds in flue gas

In this study, only the presence of unburned carbon in the FA is of interest, as this is susceptible to reach the FGD system reactor. The monthly averaged sulphur removal efficiency is presented in Figure 3. 


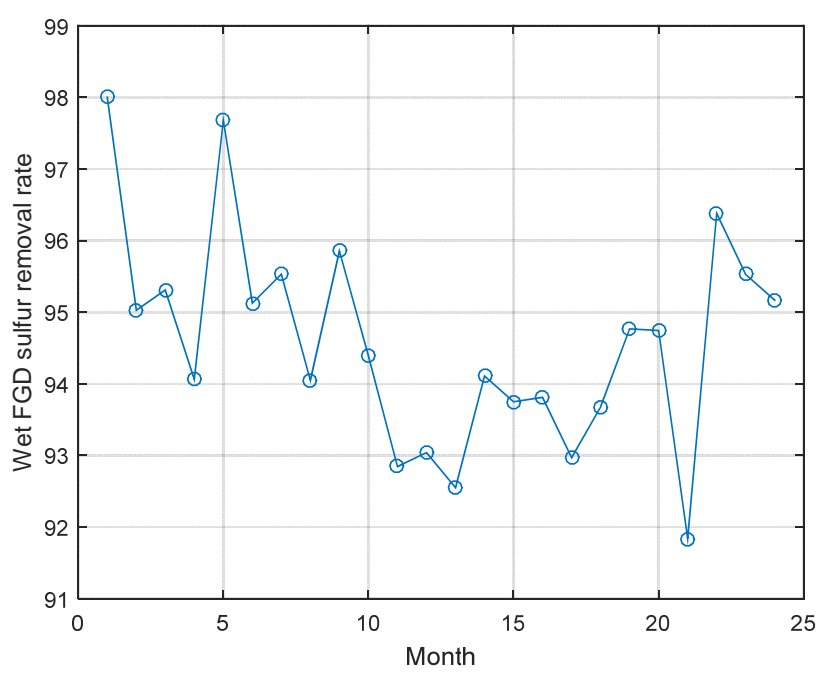

Fig. 3. FGD system efficiency throughout the analysis interval

A reverse trend can be observed, with high efficiency values corresponding to low values of unburned carbon in FA and conversely, low efficiency values for high values of the unburned carbon. Statistical analysis performed between sulphur removal efficiency values and unburned carbon in FA results in a value of the correlation coefficient of -0.78 . The value is statistically significant, although the sample volume is relatively small. The negative sign displays clearly the tendency of sulphur removal efficiency to drop at the increase of the unburned carbon in FA. A linear fit performed on unburned carbon in FA (independent variable) and sulphur removal efficiency results in the following values:

$>$ Slope: -1.29 (95\% confidence bounds: -1.74, 0.833 )

Intercept: 99.3 (95\% confidence bounds: 97.59, 101). The linear fit is presented in Figure 4.

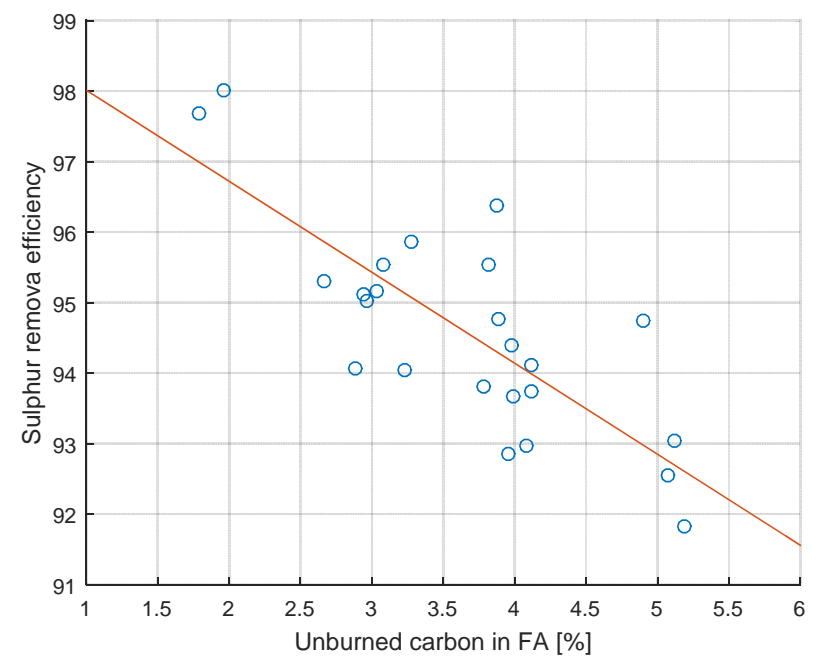

Fig. 4. Unburned carbon in FA - sulphur removal rate linear fit

\section{Conclusions}

The study presented in this paper shows quantitative evidence that incomplete combustion of coal in the boiler reduces the effectiveness of $\mathrm{SO}_{2}$ removal rate in the FGD system.

Further analysis is necessary to determine the effective amount of sulphur oxides introduced in the wet FGD system, as this is essential to calculate stoichiometrically the flow rate of limestone that is required in the system.

A quantitative analysis was carried out considering data from the power plant operation over a period of 24 months. Unburned carbon percentage in FA was correlated with the FGD sulphur removal rate in an attempt to identify a statistically significant dependence. The value of the Pearson correlation coefficient suggest that some degree of dependence exists.

If the amounts of reactive are not stoichiometric the wet FGD system cannot reach the desired removal rate, which results in exceeding the legal limits for $\mathrm{SO}_{2}$. Other consequence is deviation of the wet FGD system operation conditions from the optimum. Incomplete coal combustion (which is a consequence of a coal low quality and presence of sterile mixed with coal) is the main factor that disturbs the nominal combustion conditions resulting in the operation of the wet FGD system outside its optimum parameters range.

In order to refine the analysis, further research directions should include:

$>$ Gypsum quality and its relationship with unburned coal percentage

> Carbon monoxide and other gaseous components resulting from incomplete combustion measurement

Analysis of influence of such components on the chemical processes occurring in the FGD absorber

\section{References:}

[1] N. H. Koralegedaraa P. X. Pinto, Dionysios D. Dionysiou, S. R. Al-Abed, Recent advances in flue gas desulfurization gypsum processes and applications - A review, Journal of Environmental Management, vol.251, December 2019

[2] Andreas Poullikkas, Review of Design, Operating, and Financial Considerations in Flue Gas Desulfurization Systems, Energy Technology and Policy, vol.2, 2015 - Issue 1 
[3] A. Demirbas, M. Balat, Coal Desulfurization via Different Methods, Energy Sources 26 (2004) Issue 6

[4] A. Wheelock; Coal Desulfurization ACS Symposium Series; American Chemical Society: Washington, DC, 1977.

[5] Clyde W. Zielke, Howard E. Lebowitz, Robert T. Struck, Everett Gorin, Sulfur Removal During Combustion of Solid Fuels In A Fluidized Bed of Dolomite, Journal of the Air Pollution Control Association 20 (1970) Issue 3

[6] Lian Zhanga, Atsushi Satoa, Yoshihiko Ninomiyaa, Eiji Sasaoka, In situ desulfurization during combustion of high-sulfur coals added with sulfur capture sorbents, Fuel 82 (2003) 255-266

[7] A. Demirbas, M. Balat, Coal desulfurization via different methods, Energy Sources, vl.26, 2004 - Issue 6

[8] B. Dou, W. Pan, Q. Jin, W. Wang, Y. Li, Prediction of SO2 removal efficiency for wet Flue Gas Desulfurization, vol. 50 Issue 10, October 2009

[9] P. Cordoba, Status of Flue Gas Desulphurisation (FGD) systems from coal-fired power plants: Overview of the physic-chemical control processes of wet limestone FGDs, Fuel, vol. 144, March 2015

[10] H. Rutto, L. Koech, R. Everson, H. Neomagus, Dissolution kinetics of sorbents and effect of additives in wet flue gas desulfurization, Reviews in Chemical Engineering 30(6):553-565, December 2014

[11] A.V. Slack, H.L. Falkenberry, R.E. Harrington, Sulfur Oxide Removal from Waste Gases:, Journal of the Air Pollution Control Association, 22:3, 159-166, DOI: 10.1080/00022470.1972.10469622

[12] B. Heidel, M. Hilber, G. Scheffknecht, Impact of additives for enhanced sulfur dioxide removal on re-emissions of mercury in wet flue gas desulfurization, Applied Energy, vol. 114, February 2014

[13] L. Anghelescu, M. Cruceru, B. Diaconu: Incomplete coal combustion and factors that influence the content of unburned carbon in bottom ash - effects of incomplete combustion on the operation of the wet fgd system - a case study, Analele Universităţii Constantin Brâncuşi din Târgu-Jiu - Seria Inginerie, nr.3/2019

[14] B. Goshayeshi, J. Sutherland, A comparison of various models in predicting ignition delay in single-particle coal combustion, Combustion and Flame, vol. 161, Issue 7, July 2014
[15] J. Watanabe, K. Yamamoto, Flamelet model for pulverized coal combustion, Proceededings of the Combustion Institute, vol.35, Issue 2, 2015 